\title{
Asymmetry of atmospheric microstructure over synoptic scales
}

\author{
R. M. Worthington \\ Co-operative Institute for Research in Environmental Sciences (CIRES), University of Colorado, \\ Boulder, CO 80309-0216, USA \\ Present address: RASC, University of Kyoto, Uji, Kyoto 611-0011, Japan
}

Received: 18 October 2000 - Revised: 20 February 2001 - Accepted: 22 March 2001

\begin{abstract}
Distortions are often seen in the angular distribution of echo-power from VHF wind-profiling radars, suggesting that thin stable layers, within the air flow, are distorted and tilted from horizontal. In vertical shear of the horizontal wind, the distribution of the layer tilt angles becomes skewed. A case study using six days of VHF radar data and synoptic charts above western Europe indicates that this asymmetry of atmospheric microstructure can exist throughout the troposphere and lower stratosphere, above and below the jet wind maximum, over horizontal scales of thousands of kilometres.
\end{abstract}

Key words. Meteorology and atmospheric dynamics (middle atmosphere dynamics; synoptic-scale meteorology; turbulence).

\section{Introduction}

VHF wind-profiling radars often show interesting effects in which the angular distribution of their echo-power is tilted and/or distorted (e.g. Worthington et al., 2000). This can occur when atmospheric gravity waves, including mountain waves, tilt fine-scale VHF-reflective scattering layers (e.g. Dalaudier et al., 1994) from horizontal direction. Also, the echo-power distribution is skewed in regions of vertical shear of horizontal wind (hereafter referred to as 'shear'). This skewing implies that the average distribution function of scattering-layer tilt angles, although often centred close to horizontal and giving maximum echo-power from a verticalpointing VHF beam, is similarly skewed or asymmetric (Worthington et al., 1999a,b). Sometimes these two effects of gravity waves and shear are seen together. The observations can also sometimes be interpreted in terms of anisotropic turbulence.

The skewing of echo-power in shear may be explained if the majority of scattering layers remain horizontal on aver-

Correspondence to: R. M. Worthington

(worth@kurasc.kyoto-u.ac.jp) age, but a fraction can become tilted where localised wind shears cause Kelvin-Helmholtz instabilities (KHI) and/or a steepening of other gravity waves (e.g. Worthington et al., 1999a). Cross sections through very large-scale, well-defined KHI billows have been shown by many authors, e.g. James and Browning (1981). Even decaying remnants of KHI show an asymmetry in the tilt angles of atmospheric microstructure (Werne and Fritts, 1999, cover illustration). The sign and magnitude of the VHF echo-power variations have, in earlier studies, been shown to be consistent with a KHI type explanation (Worthington and Thomas, 1997; Worthington et al., 1999b).

Historically, effects of tilted fine-scale atmospheric layers have also been studied for radar propagation parallel, not perpendicular, to the layers (Waterman and Strohbehn 1963), with applications to line-of-sight microwave links. Effects of tilted specular scatterers are considered also by Metcalf and Atlas (1973) and Metcalf (1975), for FM-CW radar. A few studies report aspect sensitivity for wavelengths much smaller than that of VHF radar (e.g. Metcalf, 1975; Kallistratova and Petenko, 1993), implying that atmospheric microstructure may be slightly anisotropic on scales as small as centimetres.

It is not known whether the asymmetry of atmospheric microstructure implied by the VHF radar measurements is mainly a curiosity, or if there is any real greater significance. Worthington and Thomas (1997) studied only the effect of shear in lower-stratospheric inertia-gravity waves. However, asymmetry of microstructure and of VHF echo-power maps is not restricted to these waves; only a combination of shear and VHF-aspect-sensitive air is required. Therefore, this short paper considers, over synoptic scales, how widespread can be the asymmetry of VHF power distribution, and hence of atmospheric microstructure.

\section{Observations}

Figure 1 shows six days of data from the Aberystwyth VHF radar (located $52.42^{\circ} \mathrm{N}, 4.00^{\circ} \mathrm{W}$, frequency $46.5 \mathrm{MHz}$, 

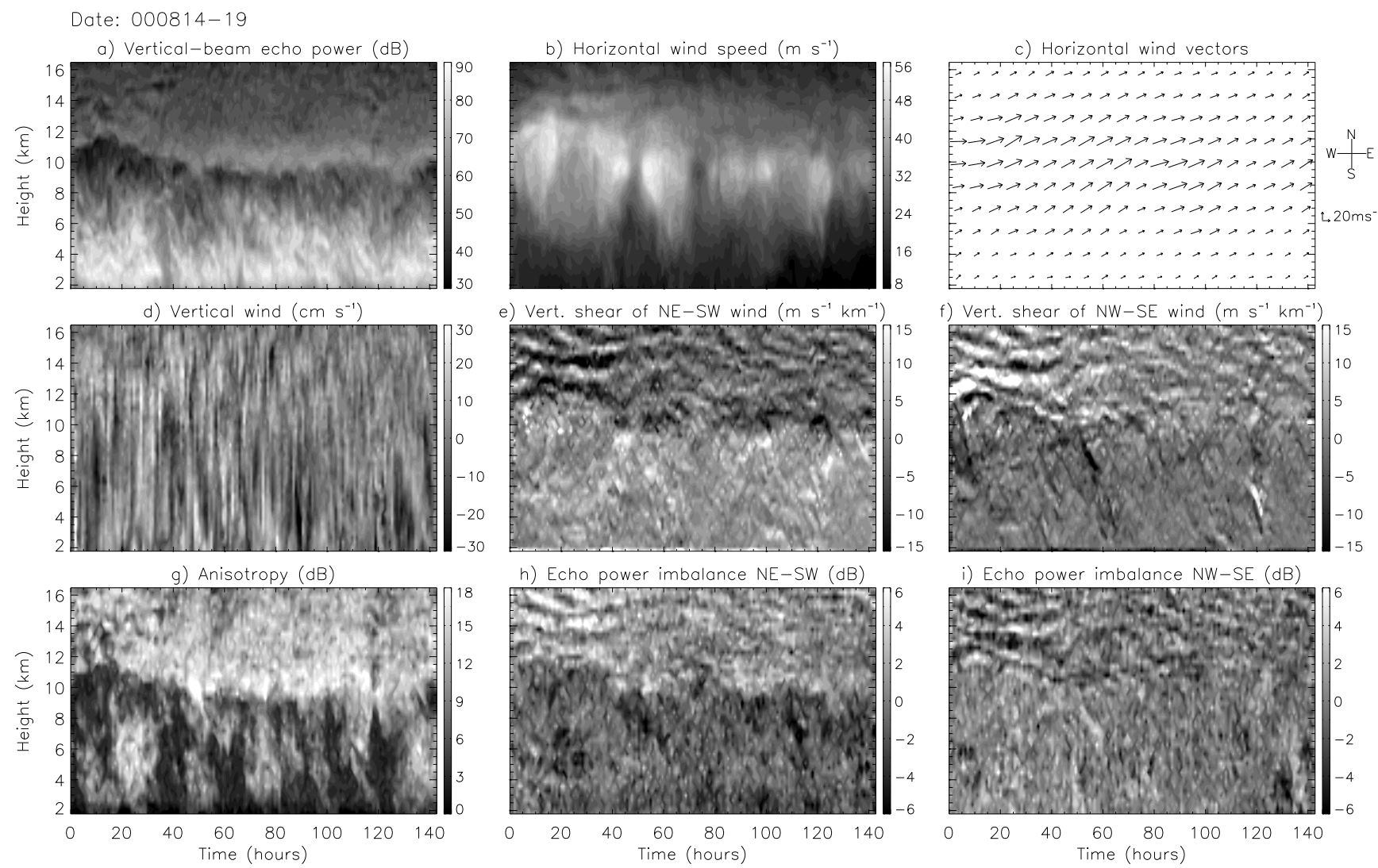

Fig. 1. Height-time plots of (a) vertical-beam echo-power, showing the tropopause height near 9-11 km, (b) horizontal wind speed, (c) horizontal wind vectors, (d) vertical wind component measured by averaging radial velocities from 2 pairs of symmetric beams $6^{\circ}$ off-vertical, (e) vertical shear of the horizontal wind component measured by the symmetric pair of beams at $6^{\circ}$ off vertical, aligned approximately NE-SW $\left(\mathrm{N} 26^{\circ} \mathrm{E}-\mathrm{S} 26^{\circ} \mathrm{W}\right)$, (f) same as (e) for the beam pair aligned approx. NW-SE (N64 $\left.{ }^{\circ} \mathrm{W}-\mathrm{S} 64^{\circ} \mathrm{E}\right)$, (g) difference between vertical and average $6^{\circ}$ echo powers to show the VHF aspect sensitivity of the air, (h) echo-power imbalance between the symmetric pair of beams aligned NE-SW, (i) same as (h) for the beam pair aligned NW-SE. The echo-power imbalances in (h) are the central observations in the paper.

height resolution $300 \mathrm{~m}$, beam width $3^{\circ}$ ). This case study is selected from several thousand days of almost continuous data, and it is fairly typical of measurements from this site.

Southwesterly jet stream winds are above the radar, Fig. $1 b$, c, with shear throughout the troposphere and lower stratosphere. The shear reverses direction at about $9 \mathrm{~km}$ height, as shown in Fig. 1e. Similarly, there is an echo-power imbalance in Fig. 1h, at all heights and for all six days, also reversing sign at about $9 \mathrm{~km}$. The VHF backscatter is aspect sensitive (anisotropy not close to zero) in Fig. 1g during most of the six days. The tropopause, shown by echo-power in Fig. 1a (see e.g. Fig. 1b of Worthington, 1998), is near the $9-11 \mathrm{~km}$ height.

Since the horizontal wind and shear in the troposphere are both toward the northeast (NE) azimuth, it would be expected (e.g. Fig. 7 of Worthington and Thomas, 1997) that the radar beam pointing upwind, toward SW, receives higher echo-power, as is observed. Much less imbalance between symmetric beams is seen in the orthogonal NW-SE azimuth (Fig. 1i).

During the six days of data, the asymmetry of atmospheric microstructure implied by the echo-power imbalance could be present in a large volume of atmosphere, advected above the radar. To put the radar results into larger-scale context, Fig. 2 shows wind vectors at $500 \mathrm{mb}$ above western Europe, centered on the radar location. Data are from the final (FNL) runs of the NCEP Global Data Assimilation System (GDAS) model. Sequences of charts at other levels are qualitatively similar. The horizontal wind in Fig. 1b, c, measured at only a single location, is seen to be part of a jet stream that remained in a fairly fixed position relative to the radar for all six days. The effect of shear on echo-power is very repeatable (e.g. Fig. 6 of Worthington and Thomas, 1997), and there is nothing unusual about the radar location relative to the jet stream structure in Fig. 2. Therefore, hypothetically, if measurements of upward-looking VHF backscatter could be made across the entire region of Fig. 2, there is no reason that the asymmetry of atmospheric microstructure indicated by Fig. $1 \mathrm{~h}$ would not also be found over large horizontal areas near the jet, implying that there are regions close to instability throughout synoptic-scale volumes of atmosphere.

These results relating to atmospheric microstructure are 


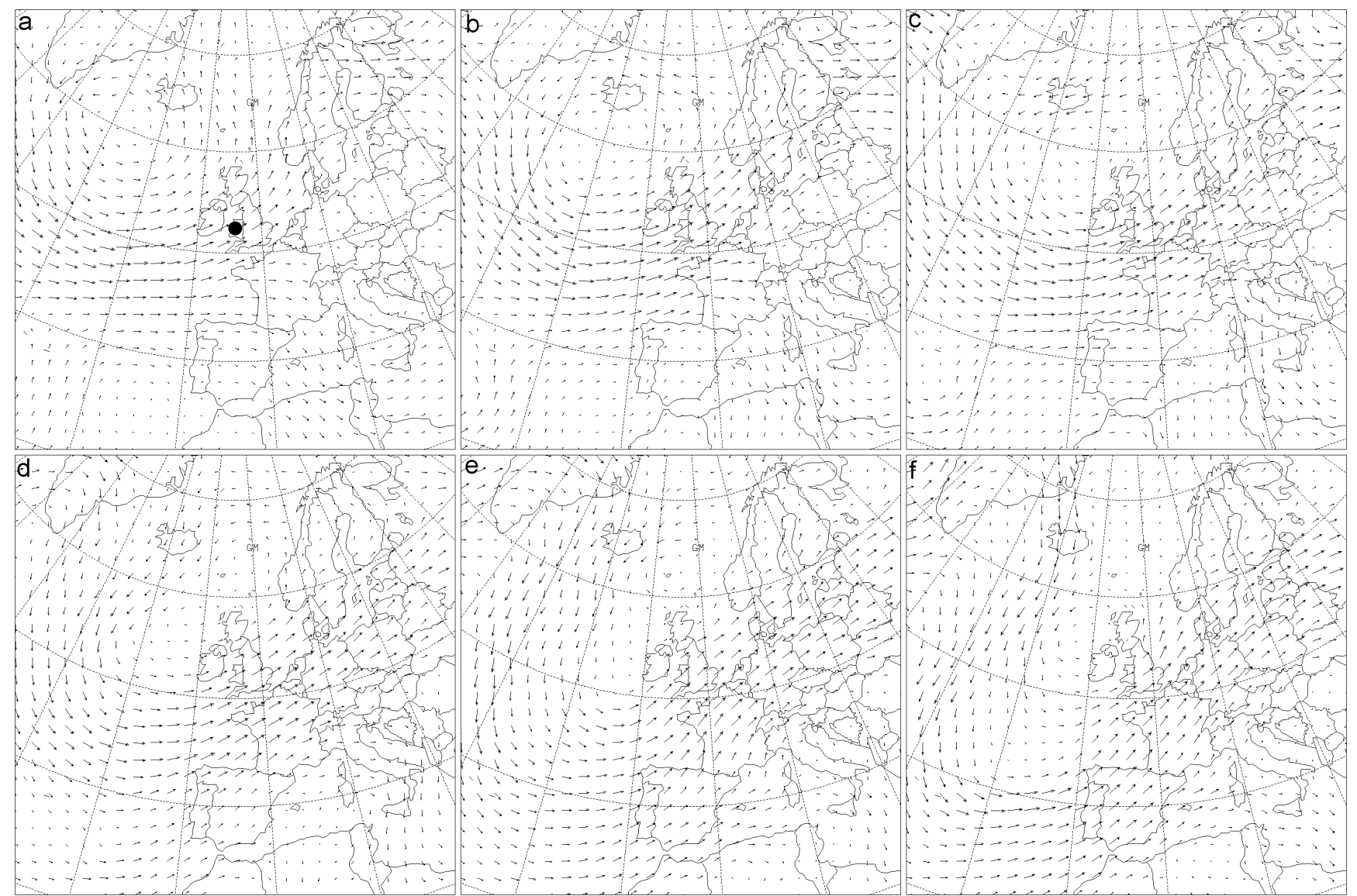

Fig. 2. Horizontal wind vectors at $500 \mathrm{mb}$ above western Europe, at 12 UTC on (a) 14, (b) 15, (c) 16, (d) 17, (e) 18, (f) 19 August 2000. The maximum vector length is $30 \mathrm{~m} \mathrm{~s}^{-1}$. In (a), a dot marks the radar location.

only inferred indirectly from radar, but it might be possible to study them in situ. For instance, Thorpe and Lemmin (1999) used lines of horizontally-spaced temperature sensors to study instabilities of internal gravity waves in a large lake. Histograms of temperature time-derivatives were not symmetric about zero, and this was interpreted as evidence for steepened internal waves. An analagous atmospheric experiment might use histograms of temperature time-derivative, measured from an aircraft flying horizontally, in shear above and below the jet stream. The flight should be parallel to the jet stream wind, since this would often be parallel to the shear vector as well, except within any inertia-gravity waves in the lower stratosphere (Worthington et al., 1999b). The asymmetry or skewing of the histograms of the temperature time-derivative is predicted to change sign, from above to below the jet maximum. Histograms of time derivatives of radar parameters, perhaps vertical-beam echo-power, could also be studied, but this remains to be explored. A similar method, but using, for example, acoustic radar in the convective boundary layer, is shown by Quintarelli (1990).

Muschinski (1996) suggests, theoretically, that an asymmetry of metre-scale atmospheric structure, as in Fig. 1h, could bias measurements of mean vertical wind $(\bar{W})$ by VHF radar. The effects of mountain waves are, however, diffi- cult to remove (Worthington et al., 2001), and there may be weak mountain waves in Fig. 1d. Figure 3 shows profiles of $\bar{W}$ averaged over all six days, with $\bar{W}$ downward in the troposphere and upward in the stratosphere. The agreement between different beam combinations in Fig. 3 is not expected for the Muschinski (1996) model, but supports a main contribution from the mountain-wave effect discussed by Worthington et al. (2001). Nevertheless, although mountain waves significantly affect $\bar{W}$ in Fig. 3, the average tilt of their streamlines (of order $\tan ^{-1}(\bar{W} / \bar{U}$ ), where $\bar{W}$ and $\bar{U}$ are average vertical and horizontal wind components) is only about $0.1^{\circ}$. Assuming a typical echo-power gradient of a few $\mathrm{dB}$ per degree of zenith angle, a $0.1^{\circ}$ tilt is insufficient to explain the $\sim 2 \mathrm{~dB}$ magnitude (or the sign) of echo-power imbalance, leaving just the KHI model to explain Fig. $1 \mathrm{~h}$.

\section{Conclusions}

Measurements by a VHF wind-profiling radar show that asymmetry or skewing in the angular distribution of echopower can be observed throughout the entire troposphere and lower stratosphere, for six days, in a fairly typical case study. Using synoptic maps, the jet stream wind structure, which 


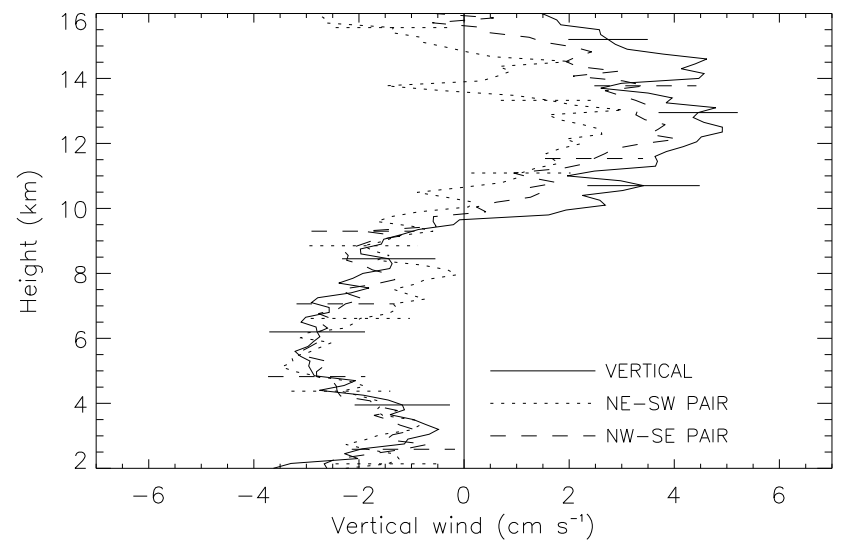

Fig. 3. Profiles of mean vertical wind $\bar{W}$ during $14-19$ August 2000 , using the vertical beam and two symmetric pairs of beams at $6^{\circ}$ off vertical. Standard errors on the means are plotted.

causes this effect, is seen to extend over much of western Europe. Since the skewing of echo-power occurs predictably in conditions of VHF aspect sensitivity and wind shear, the implied asymmetry of atmospheric microstructure may extend over a horizontal scale of thousands of kilometres. Further significance, and in situ verification remain to be explored.

Acknowledgements. Figures 2a-f are supplied by the NOAA Air Resources Laboratory. The Aberystwyth radar is a facility of the U.K. Natural Environment Research Council. RMW is supported now by a fellowship from Japan Society for the Promotion of Science.

Topical Editor J. P. Duvel thanks A. Muschinski for his help in evaluating this paper.

\section{References}

Dalaudier, F., Sidi, C., Crochet, M., and Vernin, J., Direct evidence of "sheets" in the atmospheric temperature field, J. Atmos. Sci., 51, 237-248, 1994.

James, P. K. and Browning, K. A., An observational study of primary and secondary billows in the free atmosphere, Quart. J.
Roy. Meteorol. Soc., 107, 351-365, 1981.

Kallistratova, M. A. and Petenko, I. V., Aspect sensitivity of sound backscattering in the atmospheric boundary layer, Appl. Phys. B, 57, 41-48, 1993.

Metcalf, J. I. and Atlas, D., Microscale ordered motions and atmospheric structure associated with thin echo layers in stably stratified zones, Boundary-Layer Meteorol., 4, 7-35, 1973.

Metcalf, J. I., Microstructure of radar echo layers in the clear atmosphere, J. Atmos. Sci., 32, 362-370, 1975.

Muschinski, A., Possible effect of Kelvin-Helmholtz instability on VHF radar observations of the mean vertical wind, J. Appl. Meteorol., 35, 2210-2217, 1996.

Quintarelli, F., A study of vertical velocity distributions in the planetary boundary layer, Boundary-Layer Meteorol., 52, 209-219, 1990.

Thorpe, S. A. and Lemmin, U., Internal waves and temperature fronts on slopes, Ann. Geophysicae, 17, 1227-1234, 1999.

Waterman, A. T. and Strohbehn, J. W., Reflection of radio waves from undulating tropospheric layers, J. Res. National Bureau Standards, D-Radio prop., 67D, 609-616, 1963.

Werne, J. and Fritts, D. C., Stratified shear turbulence: Evolution and statistics, Geophys. Res. Lett., 26, 439-442, 1999.

Worthington, R. M., Tropopausal turbulence caused by the breaking of mountain waves, J. Atmos. Solar-Terr. Phys., 60, 1543-1547, 1998.

Worthington, R. M. and Thomas, L., Long-period unstable gravitywaves and associated VHF radar echoes, Ann. Geophysicae, 15, 813-822, 1997.

Worthington, R. M., Muschinski, A., and Balsley, B. B., Bias in mean vertical wind measured by VHF radars: Significance of radar location relative to mountains, J. Atmos. Sci., 58, 707-723, 2001.

Worthington, R. M., Palmer, R. D., and Fukao, S., Complete maps of the aspect sensitivity of VHF atmospheric radar echoes, Ann. Geophysicae, 17, 1116-1119, 1999a.

Worthington, R. M., Palmer, R. D., and Fukao, S., An investigation of tilted aspect-sensitive scatterers in the lower atmosphere using the MU and Aberystwyth VHF radars, Radio Sci., 34, 413-426, 1999 b.

Worthington, R. M., Palmer, R. D., Fukao, S., Yamamoto, M., and Astin, I., Rapid variations in echo power maps of VHF radar backscatter from the lower atmosphere, J. Atmos. SolarTerr. Phys., 62, 573-581, 2000. 